\title{
Experimental verification and simulation of fracture behavior of CFRP reinforced self-consolidating concrete beams with initial notch
}

\author{
M. Sangi ${ }^{1}$ (D) J. Vaseghi Amiri ${ }^{1}$ G. Abdollahzadeh ${ }^{1} \cdot$ M. Dehestani $^{1}$
}

Received: 13 October 2019 / Accepted: 6 January 2020 / Published online: 24 February 2020

(c) Springer Nature Switzerland AG 2020

\begin{abstract}
The current study presents numerical and experimental approaches in the assessment of fracture behavior of self-consolidating concrete beams strengthened with carbon fiber-reinforced polymer (CFRP) lamina. The failure modes, mid-span displacement, and the load-bearing capacity of specimens with initial notches at mid-span are analyzed by varying the notch length and the beam height. Furthermore, the effects of variations in CFRP and concrete mechanical properties, bond strength, and notch location are examined by using the non-linear finite element analysis. Findings reveal that stress concentration in concrete and CFRP, in the vicinity of initial notch, as well as the failure of specimens occur as a result of CFRP debonding and crack extension. Moreover, it is observed that load- mid-span displacement curves are characterized by two peak load points strength. At the first stage, the applied load increases up to one peak value and then at the second stage there is a drop in the load-caring capacity. The applied load is then improved to another peak value due to the relatively high cohesive effect of the CFRP sheet at the third stage. Among different variables, the second peak load shows higher sensitivity to variations of the elastic modulus of CFRP, and bond strength at interface. As the notch approaches the beam support, and hence the relative distance from mid-span changes from 0 to $2 / 3$, the two peak loads are respectively escalated by 116 and $58 \%$, and thus the inclined crack propagates toward mid-span.
\end{abstract}

Keywords Notched self-consolidating concrete beam · CFRP · Mid-span displacement · Non-linear finite element approach

\section{Introduction}

In recent decades, special concretes including the selfconsolidating concrete (SCC) have been introduced to enhance the concrete performance, leading to a major advancement in the concrete technology. This type of concrete flows within the formwork with no need for internal or external vibration, and is compacted solely under the influence of its own weight. The distinctive features of this type of concrete include high deformability, flowability and segregation resistance, which cause its widespread use in different types of structures [1, 2]. Respecting SCC properties, behavioral features of conventional concrete and SCC cannot be assumed similar. Discrepancy in SCC behavior as to conventional concrete is mainly because of volume and size reduction of aggregates, as well as the inflation in cement paste volume. Leemann et al. [3] pointed out that the presence of a different transition zone in SCC can change its fracture behavior as to conventional concrete. They found that on a microscopic scale, the absence of vibration in SCC reduces the accumulated water around the aggregates, leading to lower porosity and permeability of the transition zone. Roziere et al. [4] examined the effects of cement paste volume on the mechanical properties and cracking mechanism of SCC due to shrinkage. The critical stress intensity factor $\left(\mathrm{K}_{\mathrm{ic}}\right)$, and the critical crack tip displacement $\left(C T O D_{\mathrm{c}}\right)$ were

M. Sangi, m_sangi@ymail.com | ${ }^{1}$ Department of Civil Engineering, Noshirvani University of Technology, Babol, Iran. 
thus established. The results of this study indicated that by increasing paste volume, the shrinkage and $\mathrm{CTOD}_{\mathrm{c}}$ soar.

Respecting the fracture behavior of SCC, Zhao et al. [5] examined the fracture process in SCC and normallyvibrated concrete (NVC) using a series of notched flexural specimens. They reported that the fracture energy and the characteristic length are similar for SCC and NVC. However, by inspecting the fracture toughness on 4 SCC mixtures with compressive strengths of $40-150 \mathrm{MPa}$ in notched specimens subjected to wedge-splitting tests, it was realized that the toughness values were less than the typical values for NVC defined by CEB-FIP [6]. Furthermore, Eskandari et al. [7] tested the fracture properties of SCC with low and medium strength using beams with and without notches. In this research, work of fracture $\left(G_{F}\right)$ and size effect model $\left(G_{f}\right)$ methods were used, and results were compared with those of conventional and highperformance concrete. They believed that, owing to the application of chemical and mineral admixtures, the study of micro cracks in SCC is more critical than for NVC. Beygi et al. [8-10]; and Nikbin et al. [11] considered the effects of different factors including aggregate volume, water-tocement ratio, and maximum coarse aggregate size on the mechanical behavior and fracture parameters of SCC. The results showed that the fracture energy and the toughness of specimens prepared with SCC are influenced by the above factors, thus contrasting the characteristics and behavior of this class of concrete as to conventional concrete.

Despite the advantages of SCC over conventional concrete, structures made with this type of concrete, similar to conventional concrete, demonstrate a very low tensile behavior and thus cracking occurs. However in recent years, the efforts made by researchers to retrofit old buildings or to increase flexural and shear capacity of concrete and steel members have led to new solutions in the engineering practice of retrofit and strengthening of structures $[12,13]$. In this context, the use of fiber reinforced polymer (FRP) as external reinforcement is especially significant due to its unique properties [14]. According to literature, Al-Tamimi et al. [15] experimented the flexural behavior of reinforced concrete (RC) beams cast with SCC, as well as the effect of CFRP laminate length-to-shear span ratio. The results showed that in different specimens, the failure modes comprise failure with flexural cracks, shear failure, debonding failure, sheet delamination, or a combination of these modes, depending on the strengthening extent.

It is worth noting that since FRP laminate can hinder the crack propagation in concrete and thus reduce the crack width, some analytical and numerical investigations have been conducted through finite element analysis (FEA) on the strengthening and fracture behavior of conventional concrete beams $[16,17]$.

Achintha and Burgoyne [18] employed fracture mechanics theory concerning the global energy balance, so as to estimate the load level at which the FRP sheet is debonded from the concrete substrate. They realized that the key factor pertained to fracture energy at concrete-FRP interface, and that the FRP sheet debonded in concrete at the tension reinforcement location. In addition, the reinforcing bars barred the complete evolution of fracture process zone (FPZ). The full response of beams was achieved thru relations recommended by Zheng et al. [19]. They modeled the crack propagation in concrete by using the weight function method to analyze interfacial debonding between FRP and concrete. The behavior of FRP-strengthened concrete beams was further investigated by Mohammadi et al. [20] via integrating the cohesive crack approach and the damaged concrete technique thru advanced finite element (FE) method. In addition, the intermediate crack (IC) debonding of FPR lamina was researched in specimens through tracking stress propagation at the site of main cracks, by changing the crack location relative to mid-span.

Since the mechanical properties and fracture behavior of SCC are quite different than those of conventional concrete, as well as the prominence of retrofitting structures in the aftermath of cracking, the current study conducted experimental verification and numerical simulation to investigate the effects of strengthening with CFRP lamina on the fracture mechanism of notched SCC beams subjected to threepoint bending load. Indeed, damage in concrete beams was thoroughly captured by devising a mid-span initial notch, and evaluating its rate on the response of specimens thru altering initial notch length-to-beam height ratio. To this end, bearing capacity, crack growth, and failure mode of ten SCC beams were studied in detail, by constructing specimens with initial notches and various beam heights and spans.

Moreover, specimens were modeled via a FE software. The accuracy of the modeling was verified through comparing numerical predictions with those of measured experimental results. Furthermore, parametric studies including the effect of elasticity modulus of CFRP lamina, CFRP-concrete bond strength, mechanical properties of concrete, and initial notch location on the failure mode and capacity of specimens, as well as stress distribution in concrete, CFRP, and interface were assessed so as to develop an upgraded comprehension of the performance of such structures in design and retrofit. 


\section{Experimental program}

\subsection{Material properties}

The SCC mix design used in the present study is reported in Table 1. Besides, in order to evaluate the properties of fresh SCC including flowability and segregation resistance, slump, T50, and L-box tests were carried out conforming to the European Guidelines for SCC (EFNARC [21]) and were achieved $720 \mathrm{~mm}, 3 \mathrm{~s}$ and 0.88 respectively.

The 28-day compressive strength, tensile strength, and elastic modulus of the prepared concrete are respectively 35.4 MPa, 2.7 MPa and $30.4 \mathrm{GPa}$, consistent with ASTM standards: C39, C496 and C469.

Furthermore, mechanical properties of CFRP and epoxy adhesive used for installation are presented in Table 2 , as specified by the manufacturer.

\subsection{Test specimens}

A total of ten samples of concrete notched beams, i.e. C1-4-R, C1-4-NR; C1-6-R, C1-6-NR; C1-8-R, C1-8-NR; C2-R, C2-NR; C3-R, C3-NR were constructed, that $R$ and NR is related to the strengthened specimens with CFRP and unstrengthened corresponding specimen, respectively. Figure 1 shows the geometrical properties of the CFRP reinforced specimens.

The beam width and the span-to-height ratio in all specimens were kept constant, being respectively $150 \mathrm{~mm}$ and 4. In specimens G1-4-R, G1-6-R and G1-8-R, the initial notch length to beam height ratio (i.e. $a_{0} / h_{s}$ ), was $0.2,0.3$ and 0.4 , and the beam height remained unchanged equal to $200 \mathrm{~mm}$. Likewise, in beams G1-6-R, G2-R and G3-R, the $\mathrm{a}_{0} / \mathrm{h}_{\mathrm{S}}$ ratio was constant being as 0.3 , and the beam height varied by 200,250 and $300 \mathrm{~mm}$.where $b_{s}$ is the section width, $h_{\mathrm{s}}$ the beam height, $b_{f}$ and $h_{f}$ respectively the width and height of CFRP lamina, $a_{0}$ the initial notch length, and $L$ and $L_{f}$ are the beam span and CFRP lamina length, in order.

Once surface preparation was performed, concrete beams were reinforced with the CFRP lamina with a

Table 1 Detailed concrete compositions (unit: $\mathrm{kg} / \mathrm{m}^{3}$ )

\begin{tabular}{ll}
\hline Material & Weight $\left(\mathrm{kg} / \mathrm{m}^{3}\right)$ \\
\hline Cement & 500 \\
Sand & 650 \\
Gravel & 600 \\
Water & 238 \\
Superplasticizer & 4 \\
Limestone powder & 380 \\
\hline
\end{tabular}

Table 2 Mechanical properties of CFRP and adhesive (according to the manufacturer)

\begin{tabular}{lll}
\hline Property & Adhesive & CFRP \\
\hline Elastic modulus & $3.52 \mathrm{GPa}$ & $240 \mathrm{GPa}$ \\
Tensile strength & $42.61 \mathrm{MPa}$ & $3.9 \mathrm{MPa}$ \\
Ultimate strain & $1.2 \%$ & $1.7 \%$ \\
Poisson's ratio & 0.4 & 0.2 \\
\hline
\end{tabular}

thickness of $0.167 \mathrm{~mm}$, a width of $150 \mathrm{~mm}$ and $\mathrm{L}_{\text {frp }} / \mathrm{L}$ ratio of 0.9 .

\subsection{Test set-up and instrumentation}

The three-point bend load of rate $0.2 \mathrm{~mm} / \mathrm{s}$ was applied to all specimens in displacement-controlled mode. Load $(P)$ and mid-span displacement $(\delta)$ were logged respectively via a universal testing device set up, having a load cell of capacity 150 kN (Fig. 2).

\subsection{Test results}

The failure process of all beams takes place in four stages which are presented in Fig. 3a-d. This process is similar for all specimens in a sense that by applying force, initial crack is vertically extended to approximately half the beam cross-section height. Then, along with the vertical crack growth, the crack mouth opening also increases, elevating the stress in the lamina. Since these stresses are higher than the failure limit of the adhesive, this layer fails during the transfer of concrete stress to lamina, leading to specimen failure as the lamina is debonded from the concrete surface. The debonding is initiated at the notch location due to the concentration of shear stresses and then propagates toward the support with increasing of load.

The load-displacement curves of strengthened beams (RF) and the corresponding unstrengthened samples (NF) are compared in Fig. $4 a-c$ for samples of different beam height.

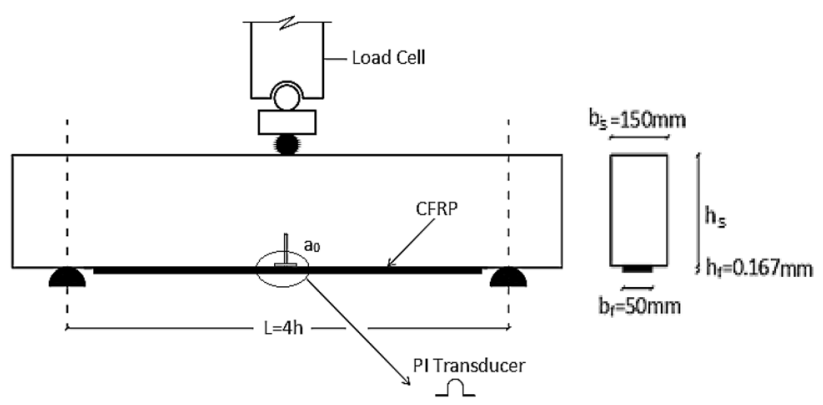

Fig. 1 Geometry of CFRP-strengthened concrete beam 


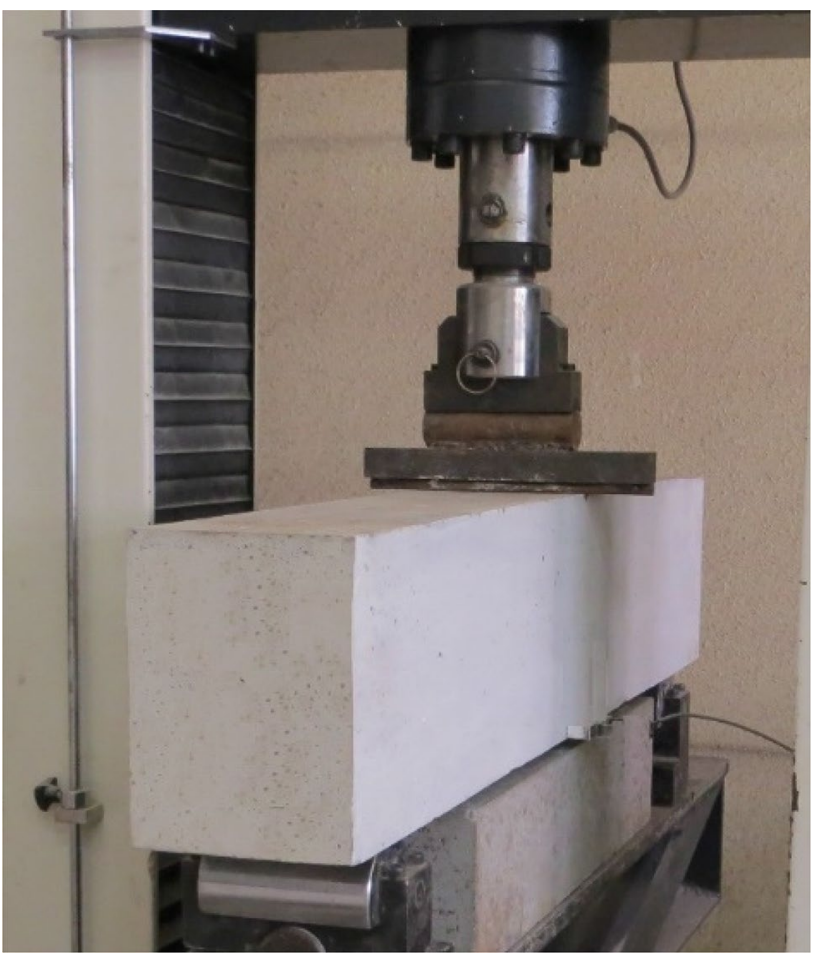

Fig. 2 Test set up

In addition, $\mathrm{P}-\delta$ curves concerning the CFRP-strengthened beams (RF) and the corresponding unstrengthened specimens (NF) are depicted in Fig. $5 \mathrm{a}-\mathrm{c}$ respectively for beams with $\mathrm{a}_{0} / \mathrm{h}_{\mathrm{S}}=0.2,0.3$ and 0.4 .

The results indicate that although retrofitting of specimens with CFRP does not significantly escalate the first peak load capacity $\left(\mathrm{P}_{1 \max }\right)$, it considerably increases ductility of the specimens. As it is witnessed, with load increase and crack evolution on the section of unstrengthened specimens, the capacity is reduced to zero after reaching its maximum value; while the presence of CFRP in strengthened specimens prevents the capacity from being zero, hence, increasing the capacity up to the second peak point $\left(\mathrm{P}_{2 \max }\right)$. In other words, strengthened specimens are able to withstand higher deformations as compared to corresponding unstrengthened (NF) specimens.

Since test specimens consist of three sections of concrete, adhesive and CFRP lamina, the strength of each section influences the failure mode and the rate of crack development. Based on the results stated above, behavior of specimens can be analyzed accordingly: In the first step, due to a slight slip between concrete and CFRP lamina, the entire beam, specifically the concrete, sustain the stresses as the force is applied. Thus, load reaches the first peak point $\left(P_{1 \text { max }}\right)$ as crack propagates, yet debonding has not been initiated. The load-bearing capacity is then reduced once slippage occurs at the concrete- lamina interface. In the next step, as the midspan displacement expands, tensile stresses increase in the CFRP lamina and the load reaches the second peak point $\left(P_{2 \max }\right)$ on account of the lamina presence. Subsequent loading leads to the lamina debonding off the concrete surface due to the concentration of shear stresses in the vicinity of mid-span. The full crack propagation then results in the specimen failure.

The load bearing capacity and the rate of midspan displacement in specimens with different initial notch lengths and variable section depth are compared in Figs. 6 and 7 , respectively.
Fig. 3 Failure process of specimens: a vertical growth of initial notch; $\boldsymbol{b}$ increase in crack mouth opening; $\mathbf{c}$ initiation of CFRP lamina debonding at notch location; d debonding extension up to the support

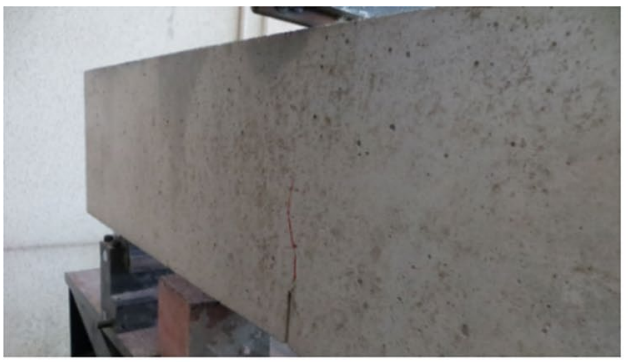

(a)

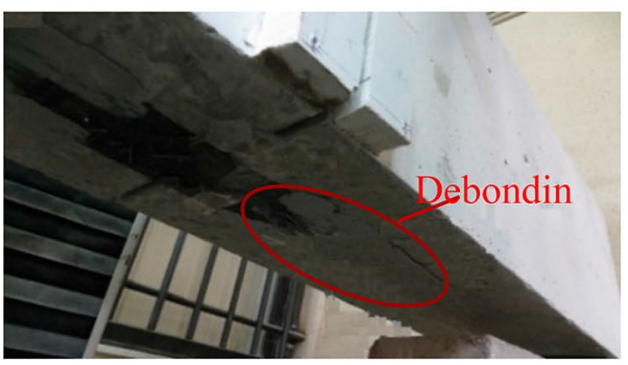

(c)

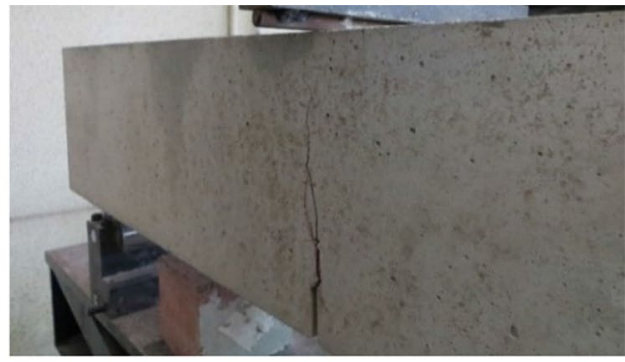

(b)

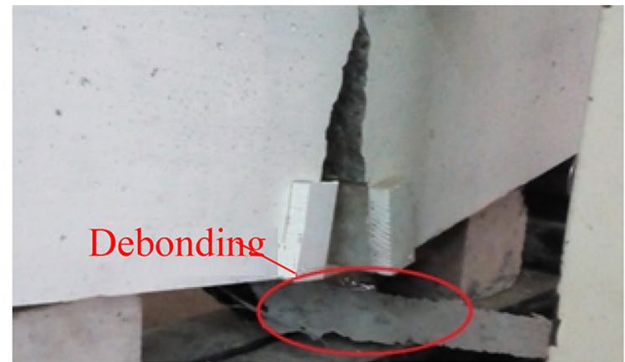

(d) 


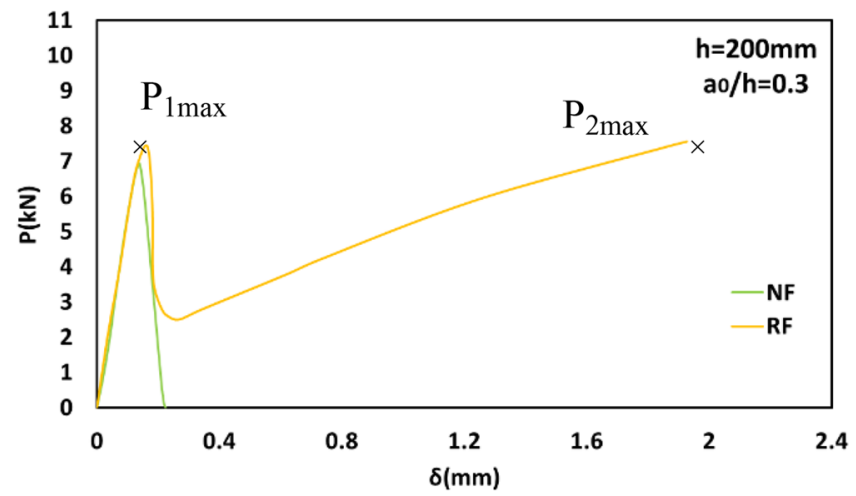

(a)

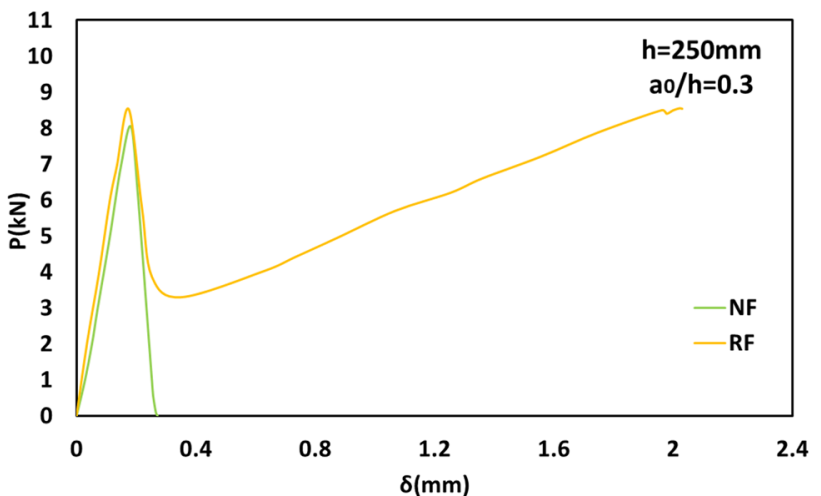

(b)

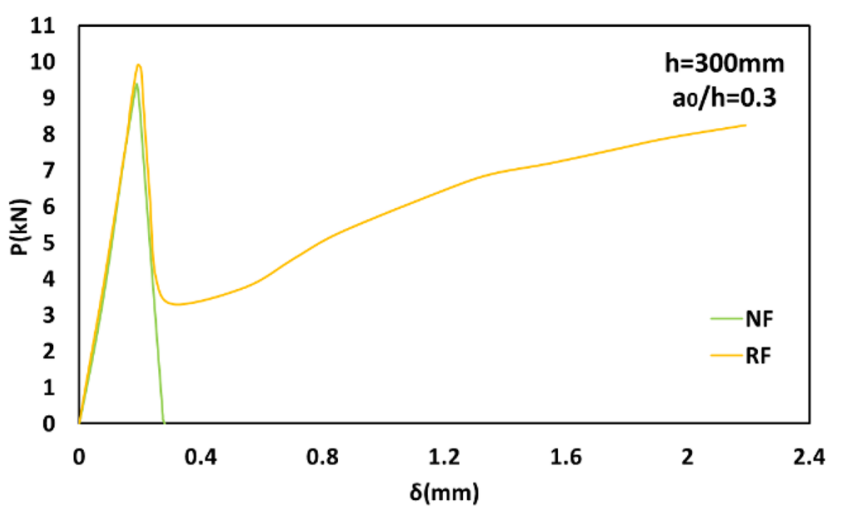

(c)

Fig. 4 P- $\delta$ curve comparison for different strengthened and unstrengthened beams: $\mathbf{a} h_{S}=200 \mathrm{~mm} ; \mathbf{b} h_{S}=250 \mathrm{~mm} ; \mathbf{c} h_{S}=300 \mathrm{~mm}$

The results specify that as crack length increases, $\mathrm{P}_{1 \max }$ is reduced, however, $P_{2 \max }$ holds nearly invariable. Because by increasing the crack length, the bearing capacity of concrete beam will be reduced. Moreover, when the beam height is increased $100 \mathrm{~mm}$, the two peak loads respectively increment 30 and $10 \%$. The main reason to this is that, when the section depth increases, moment of inertia is elevated at critical section, leading to an increase in the beam's flexural strength, and a subsequent increase in peak points.

\section{Numerical simulation}

The fracture behavior of CFRP-strengthened initiallynotched concrete beams along with the notch extension were also numerically investigated with the aid of FEA using Abaqus v. 6.14. The characteristics of models were selected based on the examined experimental specimens in order to carry out simulations. Numerical predictions were compared with those of experimental results obtained in this research, and then the accuracy of numerical modeling was verified. Results were thereby implemented for other numerical case analyses.

\subsection{Material properties and constitutive models}

Solid and shell elements were respectively assigned to model the concrete and CFRP lamina. Likewise, the adhesive layer was modeled via cohesive elements. CFRP was assumed to exhibit linear behavior, such that the stress-strain diagram is linear up to failure point, at which material loses its ultimate capacity. A concrete damaged plasticity technique was then employed to model the failure of concrete, which is attributable to cracking in tension or compression.

The extended FE method (XFEM), as being an efficient approach for modeling cracks in Abaqus, was adopted to simulate cracking in the current study. In this method, it is possible to capture discontinuities including cracks in an element. To be specific, XFEM can constantly probe the crack propagation. The criterion for crack opening is regarded the maximum stress, and hence the crack extends as the energy of each element reaches the defined failure level. 


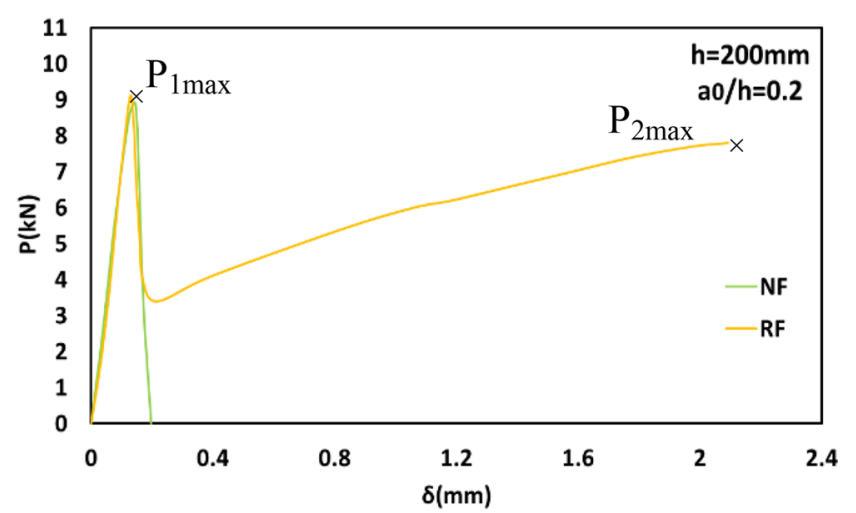

(a)

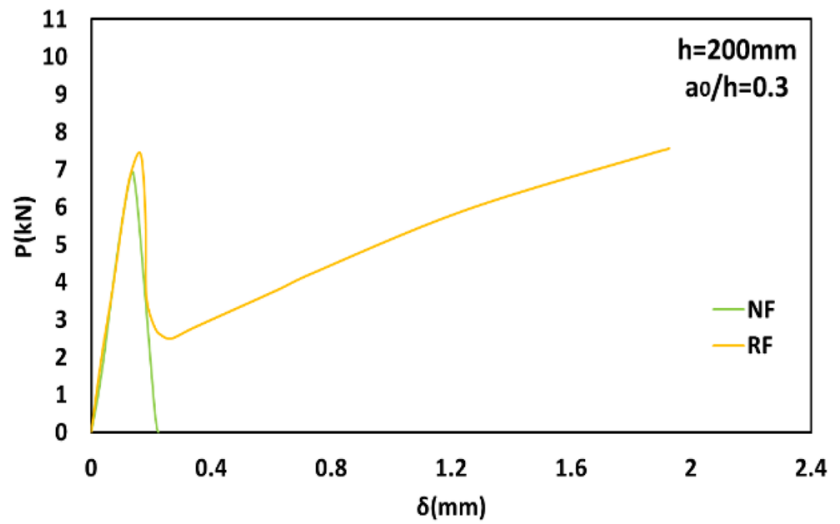

(b)

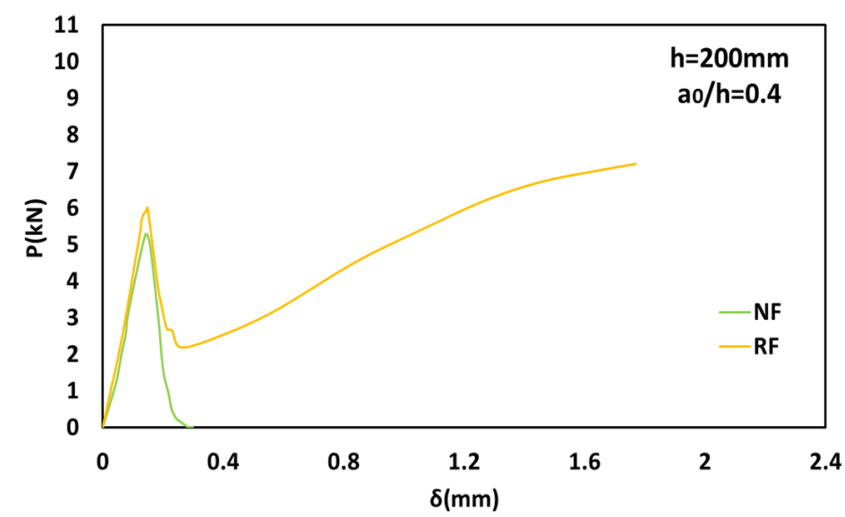

(c)

Fig. 5 P- $\delta$ curve comparison for different strengthened and unstrengthened beams: $\mathbf{a} a_{0} / h_{S}=0.2 ; \mathbf{b} a_{0} / h_{S}=0.3 ; \mathbf{c} a_{0} / h_{S}=0.4$

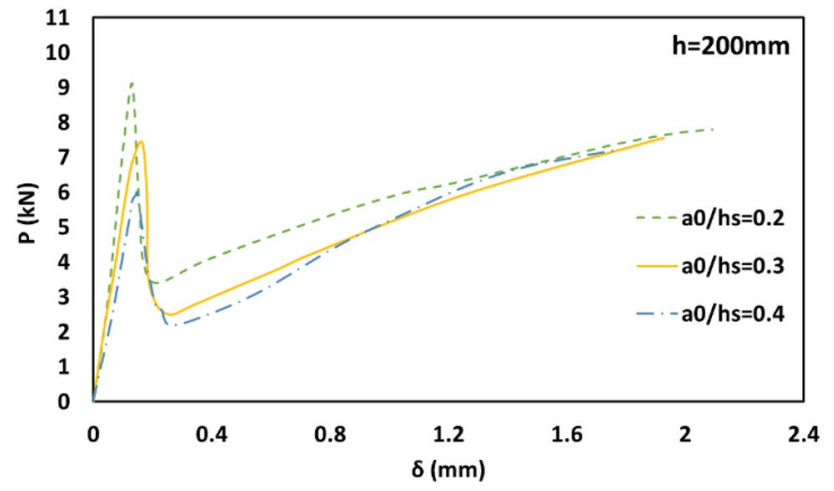

Fig. 6 Changes of $\mathrm{P}-\delta$ with variation of $\mathrm{a}_{0} / \mathrm{h}_{\mathrm{s}}$ ratio

\subsubsection{Concrete}

Different forms of concrete softening curves have been already proposed throughout the literature [22]. In the present study, the concrete strain softening curve under uniaxial tension used to develop concrete damaged plasticity model was adopted, as shown in Fig. 8. The linear strain softening of concrete was determined by

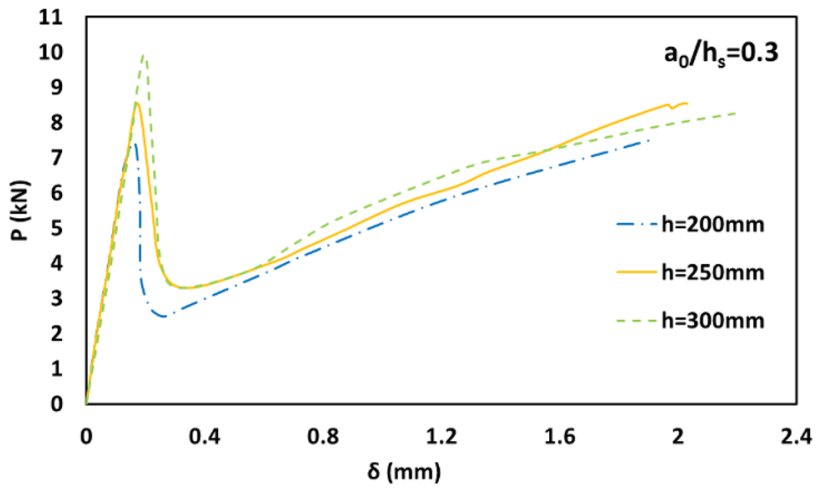

Fig. 7 Changes of $\mathrm{P}-\delta$ with variation of specimen depth

the fracture energy $\left(\mathrm{G}_{f}\right)$ and the maximum load-bearing stress $\left(f_{t}\right)$. The elastic properties of concrete conform to those of the experiment, and the fracture energy of SCC was taken to be $0.035 \mathrm{~N} / \mathrm{mm}$, based on the studies conducted by Beigi et al. [10] via size-effect method. 


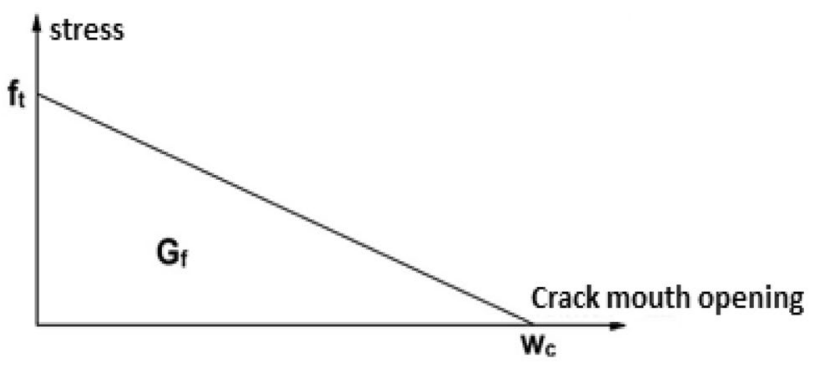

Fig. 8 Concrete strain softening curve is linearly approximated

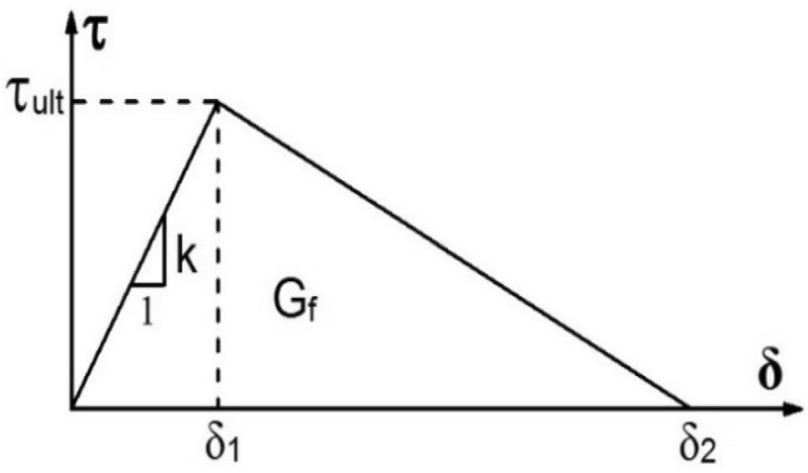

Fig. 9 CFRP-concrete interaction behavior

\subsubsection{CFRP lamina and adhesive layer}

The properties of CFRP lamina were applied in the software according to Table 2 , and the failure criteria was considered to be the ultimate stress and strain of CFRP. For the adhesive, a layer with $0.1 \mathrm{~mm}$ of thickness was defined and then the mechanical properties were assigned to it. The behavior of the materials were selected cohesive for the interaction region which were based on the traction-separation laws provided by the Abaqus software. The concrete-CFRP lamina interaction region (adhesive) was characterized by the fracture energy and the ultimate stress, in that once energy and stress of each element exceeded the fracture limit, the applied stresses could not be resisted by that element, and thus failure would occur. The shear stress $(\tau)$ is correlated with slip ( $\delta)$ at the interface of CFRP-to-concrete considering the bi-linear function proposed by Lu et al. [23], show in Fig. 9.

Where $\tau_{\text {ult }}$ is the adhesive maximum shear strength, $\delta_{1}$ is the slip corresponding to $\tau_{\text {ult }}$ and $\delta_{2}$ is the ultimate slip when the shear stress declines to zero. Consistent with Lu's model, as well as the empirical investigations [23], the interaction parameters are computed accordingly:

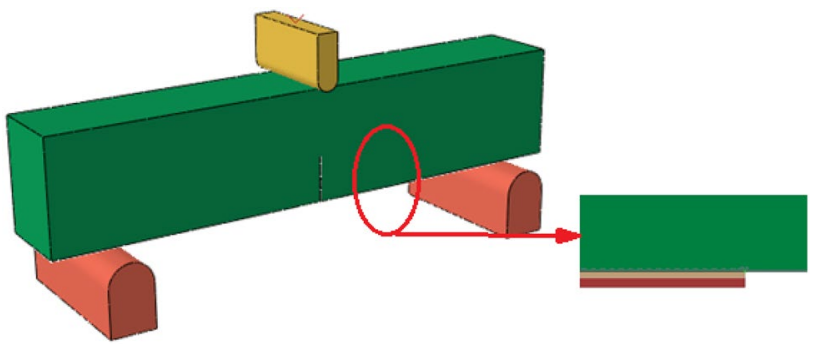

Fig. 10 Finite-element model of notch beams strengthened with CFRP

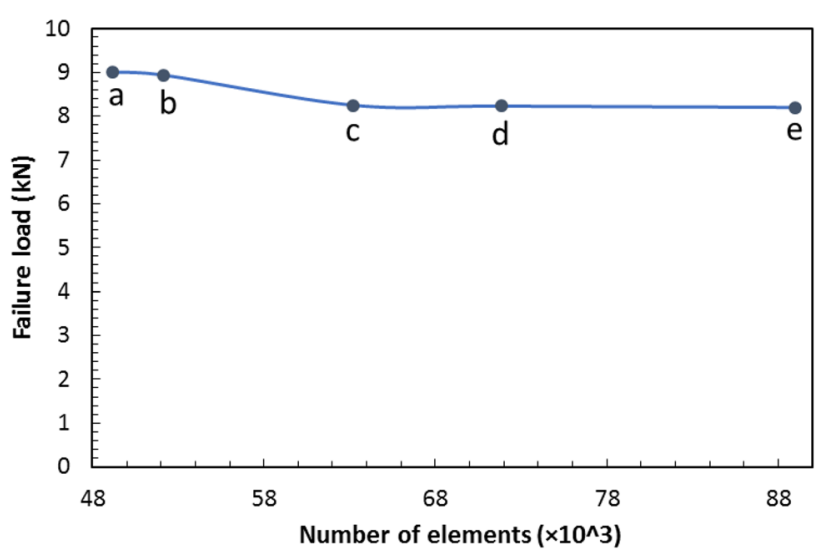

Fig. 11 The effect of number of elements on failure load

$\tau_{u l t}=1.5 \beta_{w} f_{t}$

$G_{f}=0.308 \beta_{w}^{2} \sqrt{f_{t}}$

$\beta_{w}=\sqrt{\frac{2.25-b_{f} / b_{c}}{1.25+b_{f} / b_{c}}}$

where $f_{t}(\mathrm{MPa})$, is the concrete tensile strength, $G_{f}(N / m m)$ the interfacial fracture energy of concrete, $b_{c}$ and $b_{f}$ are the width of CFRP lamina and concrete section, respectively. Based on the above relations, the failure shear stress and fracture energy of the interaction region are $4.46 \mathrm{MPa}$ and $0.61 \mathrm{~N} / \mathrm{mm}$, respectively. The 3D FE analysis model generated in ABAQUS software is depicted in Fig. 10.

A total of five meshes with different element size (a-e) were compared for the C1-4-F specimen, so as to establish an accurate size for the elements in FE models. The failure load $\left(\mathrm{P}_{2 \max }\right)$ attained from the number of elements are presented in Fig. 11.

Given the acceptable agreement between the modeling estimates of mesh $\mathrm{c}$ with those of the experimental results, and due to convergence, this mesh size was 
selected in the FE modeling of all specimens throughout this study. Besides, since elements are sensitive to crack propagation, mesh size was made finer in the proximity of the crack, and thus coarser on non-sensitive parts, as shown in Fig. 12.

\subsection{Numerical results}

The $\mathrm{P}-\delta$ curves achieved from experiments and numerical estimations are compared respectively in Figs. 13 and

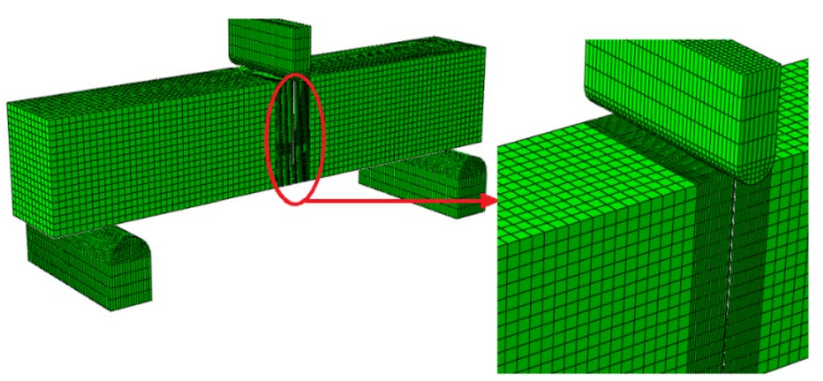

Fig. 12 Finite-element mesh of notch beams strengthened with CFRP

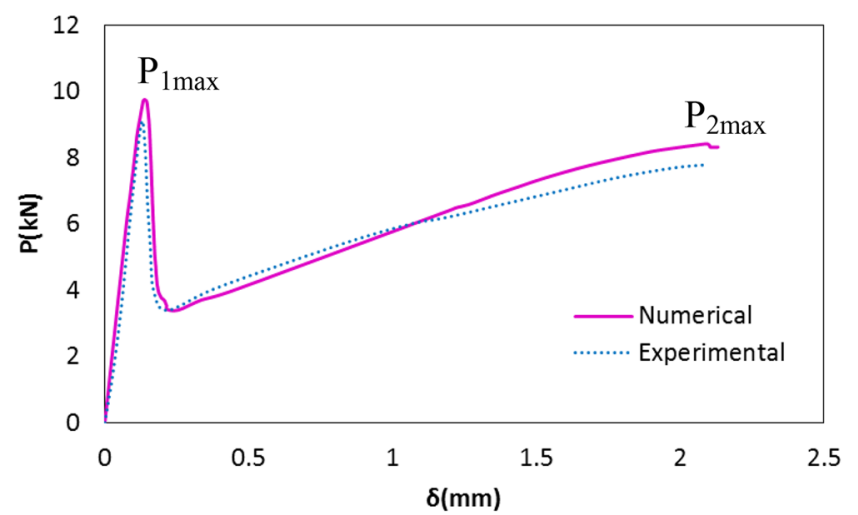

(a)
14 , concerning different ratios of $\mathrm{a}_{0} / \mathrm{h}$ and various beam heights. As it is observed, trend of variations in figures are quite akin, regarding numerical and experimental approaches. In this sense, the load change is initially linear with respect to midspan displacement, and then it shows a non-linear behavior after the crack extension; once $\mathrm{P}_{1 \text { max }}$ is reached concurrently with the vertical crack growth up to load point, the bearing capacity is reduced followed by a sharp decrease in the curve; the capacity is then increased when CFRP takes effect until $P_{2 \max }$ is reached, and then stress considerably increases in the lamina. Also, the values of $\mathrm{P}_{1 \mathrm{max}}, \mathrm{P}_{2 \max }$ obtained for all specimens, also are compared in Fig. 15.

It should be noted that difference between $P_{1 \max }$ and $P_{2 \max }$ points, obtained from the experimental investigations compared to modeling predictions in the current study is less than $10 \%$, and thereby a fairly good agreement is demonstrated. Given the symmetry of specimens, the stress distribution obtained thru numerical simulation is plotted in Fig. 16 for half the adhesive layer.

It is worth noting that the adhesive elements' stresses increment at mid-span, leading to debonding of CFRP lamina in this area as the failure limit is reached. With

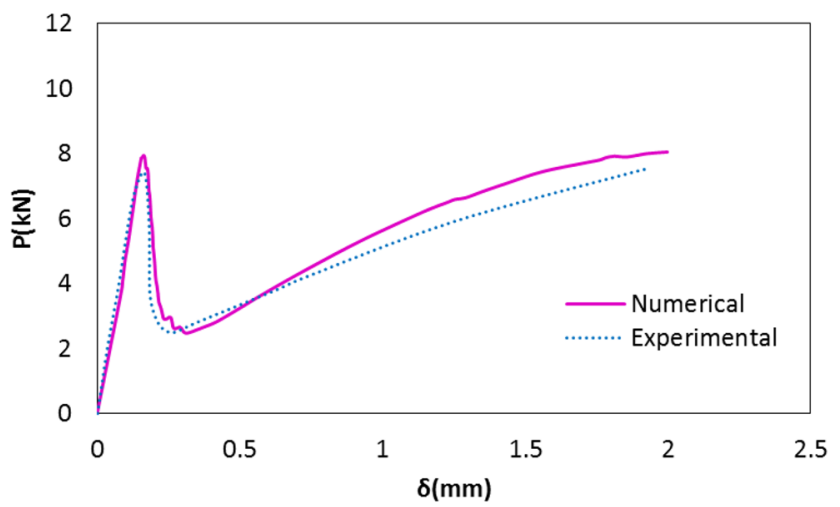

(b)

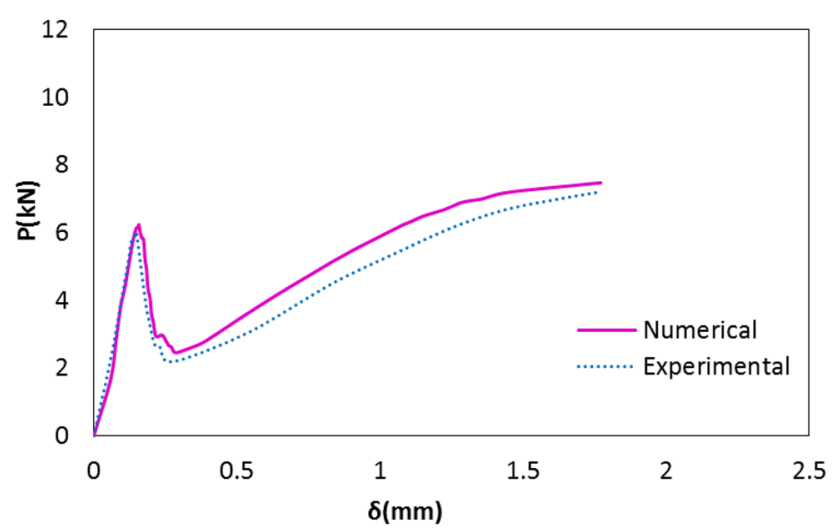

(c)

Fig. 13 Comparison of $P-\delta$ curves with variation of $a_{0} / h_{s}$ ratio: $\mathbf{a} a_{0} / h_{s}=0.2 ; \mathbf{b} a_{0} / h_{s}=0.3 ; c a_{0} / h_{s}=0.4$ 


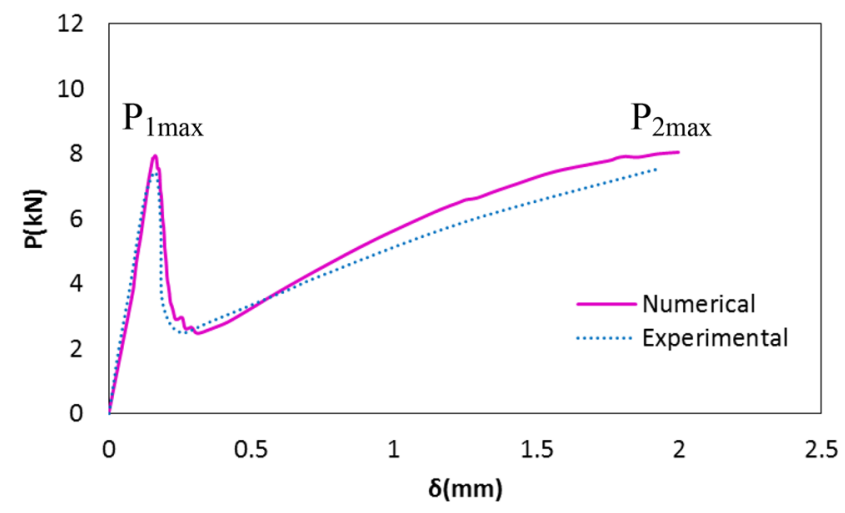

(a)

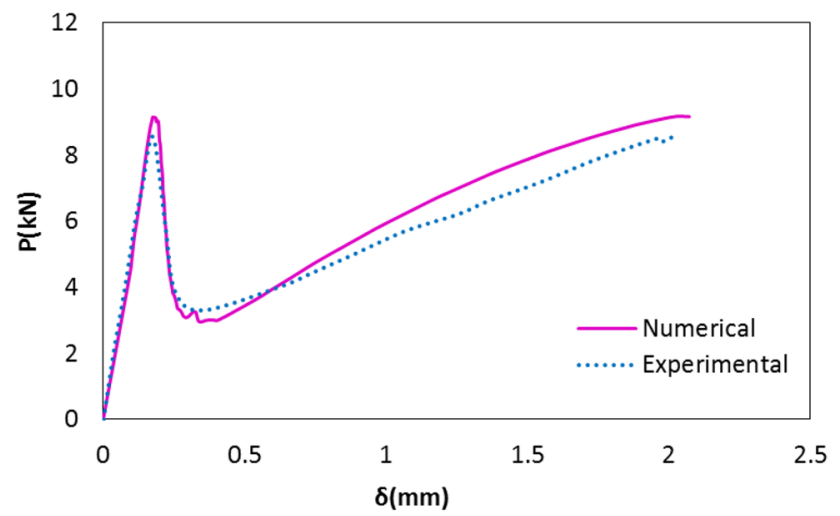

(b)

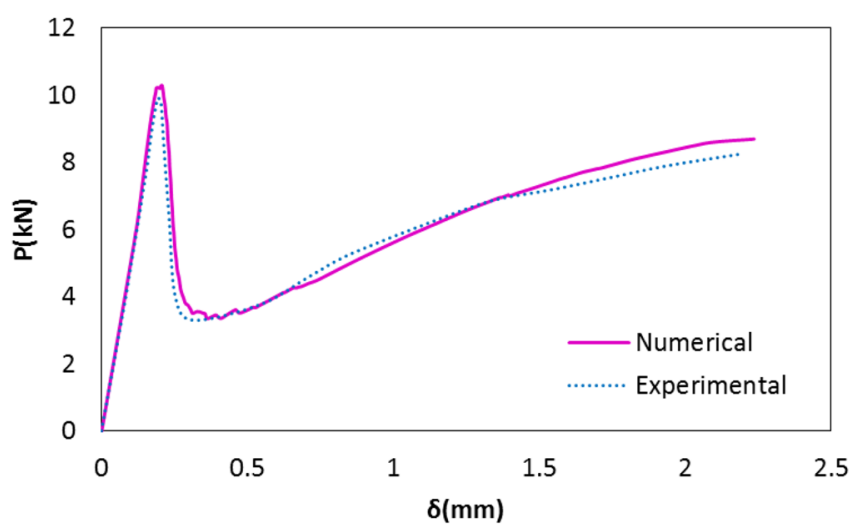

(c)

Fig. 14 Comparison of $\mathrm{P}-\delta$ curves with variation of section depth: $\mathbf{a} \mathrm{h}=200 \mathrm{~mm} ; \mathbf{b} \mathrm{h}=250 \mathrm{~mm} ; \mathbf{c} \mathrm{h}=300 \mathrm{~mm}$

Fig. 15 The maximum bearing loads versus change in initial notch length and height of the section

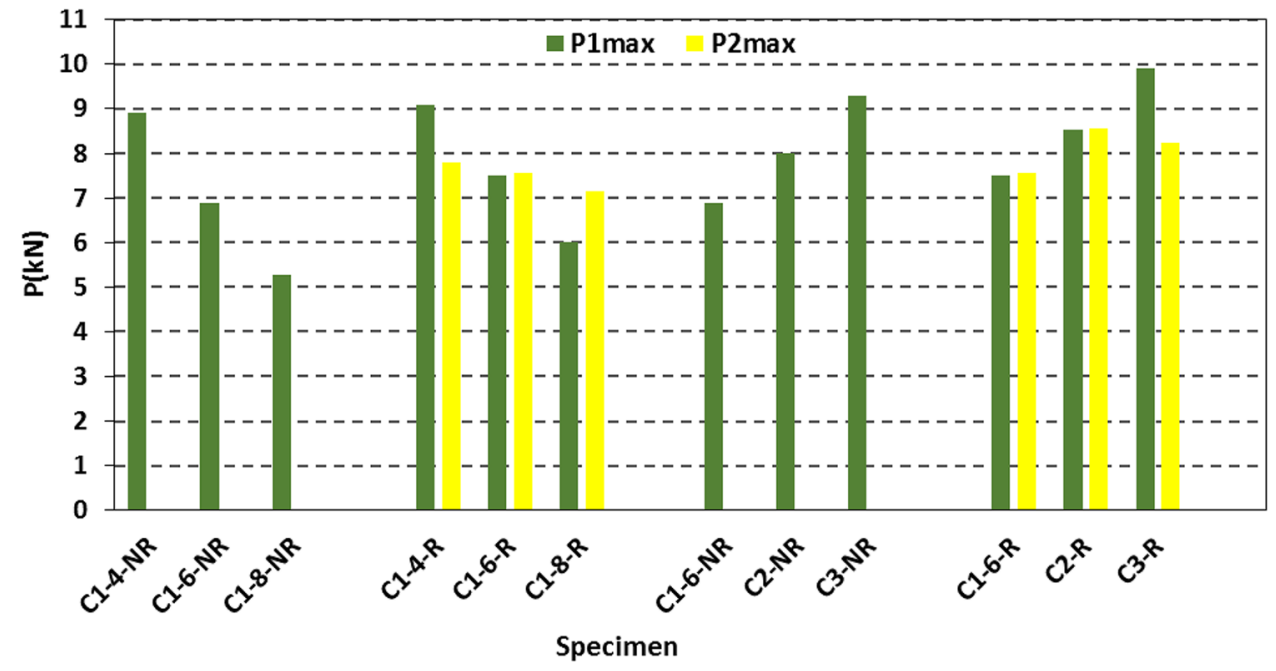

this mechanism transmitting across the adhesive, debonding moves toward the supports and hence the failure mode turns to be similar to that of the experimental results.

In accordance with the findings, a reasonable agreement exists between numerical modeling and experimental measures in various attributes, indicating that the results from numerical analyses are reliable when all three parts of the beam are modeled using the FE approach. 


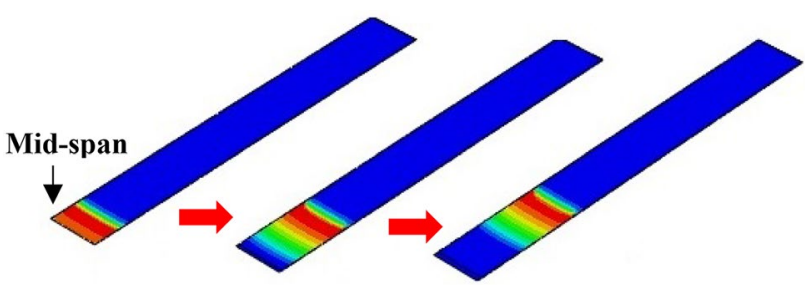

Fig. 16 Stress distribution along the adhesive layer

\section{Parametric analysis}

Having verified the accuracy of modeling through comparing numerical predictions with those of measured experimental results, parametric analyses are conducted for the specified CFRP-strengthened notched beam by varying the CFRP lamina elastic modulus, adhesive strength, concrete mechanical properties and the crack distance from mid-span. Throughout the analyses, element and modeling types comply with those of the validation part, i.e. section width and height of specimens are respectively 150 and $200 \mathrm{~mm}$, and the span length is $800 \mathrm{~mm}$.

\subsection{The effect of CFRP lamina stiffness}

Since the CFRP lamina mechanical property is a viable influential parameter on the failure mode of specimens, here in the effect of variation in the CFRP elastic modulus is explored. Mechanical properties of concrete are kept constant, $\mathrm{a}_{0} / \mathrm{h}_{\mathrm{s}}$ ratio is 0.3 , and the modulus of elasticity is considered to be $\mathrm{E}, 1.5 \mathrm{E}$ and $2 \mathrm{E}$, where $\mathrm{E}$ is the CFRP elastic modulus given in Table 2 . The $P-\delta$ curve for beams with different CFRP elastic moduli is depicted in Fig. 17.

As it is seen, the maximum points are elevated as the elastic modulus increases, because lamina with bigger modulus of elasticity tolerate larger tensile forces. As the elastic

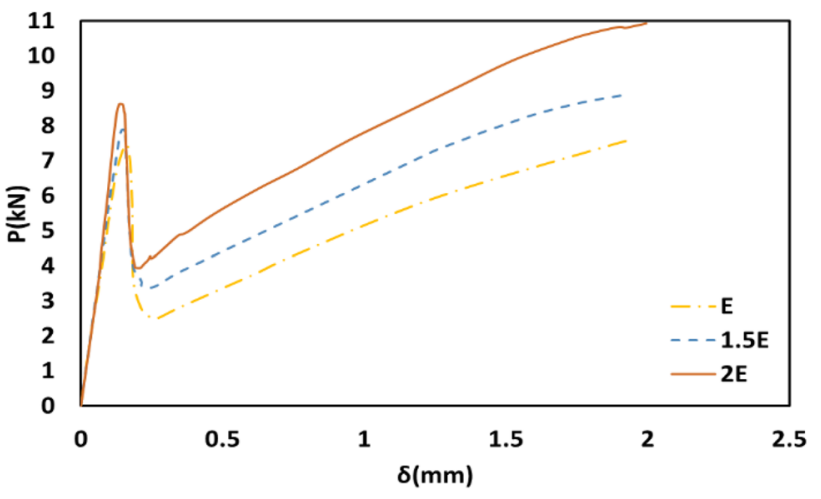

Fig. 17 Comparison of $\mathrm{P}-\delta$ curve by variation in CFRP modulus of elasticity modulus is doubled, the first peak point rises by $16 \%$ and the second grows by $45 \%$. Hence, it is discerned that the effect of sheet elastic modulus on the second peak load is more pronounced.

\subsection{The effect of CFRP-to-concrete bond strength}

The impact of interaction parameters on the load-displacement is evaluated in this section. CFRP lamina properties are reported based on numerical simulations in Table 2; concrete has a strength of $35 \mathrm{MPa}$ and the length of initial notch is $60 \mathrm{~mm}$.

Having quantified the concrete and CFRP bond parameters through Eq. (1), was moderated by factor $Y$. The peak loads are plotted versus $Y$ in Fig. 18. The reduction factor $Y$ is applied so as to denote the influence of environmental degrading elements and construction impediments on the concrete-CFRP bond in the course of its service life. $\Upsilon$ equal to zero is correspond to completely degrade and $\Upsilon$ equal to 1 represented perfect bond between concrete and lamina.

Obviously, both peak loads increment with increasing adhesive strength. According to results, $\mathrm{P}_{1 \max }$ and $\mathrm{P}_{2 \max }$ rise by 50 and $70 \%$, respectively. Consequently, the adhesive strength plays a significant role on the lamina performance.

\subsection{The effect of mechanical properties of concrete}

It is apparent that once concrete compressive strength is altered, more mechanical properties will be refined. In this regard, following CEB-FIP [6], the tensile strength $\left(\mathrm{f}_{\mathrm{t}}\right)$, elastic modulus $\left(E_{c}\right)$ and fracture energy of concrete $\left(G_{f}\right)$ are achieved according to the following relationship

$f_{t}=0.3\left(f_{c k}\right)^{2 / 3}$

$E_{c}=21.5 \times 10^{3}\left(\frac{f_{c k}+8}{10}\right)^{1 / 3}$

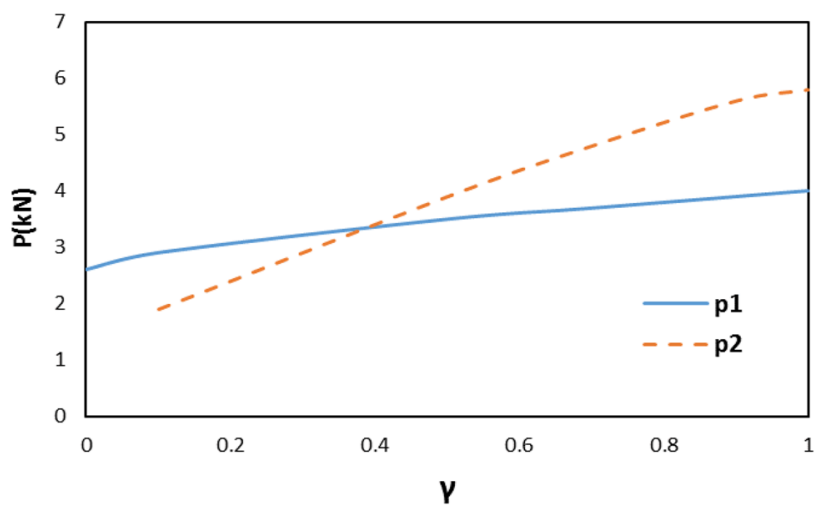

Fig. 18 Impact of interfacial bond strength on the two peak loads 
Table 3 Mechanical properties of concrete in numerical analysis

\begin{tabular}{lll}
\hline Compressive strength (MPa) & Tensile strength (MPa) & $\begin{array}{l}\text { Elastic } \\
\text { modulus } \\
(\mathrm{GPa})\end{array}$ \\
\hline 20 & 2.2 & 30 \\
35 & 2.7 & 30.4 \\
50 & 4.1 & 38.63 \\
\hline
\end{tabular}

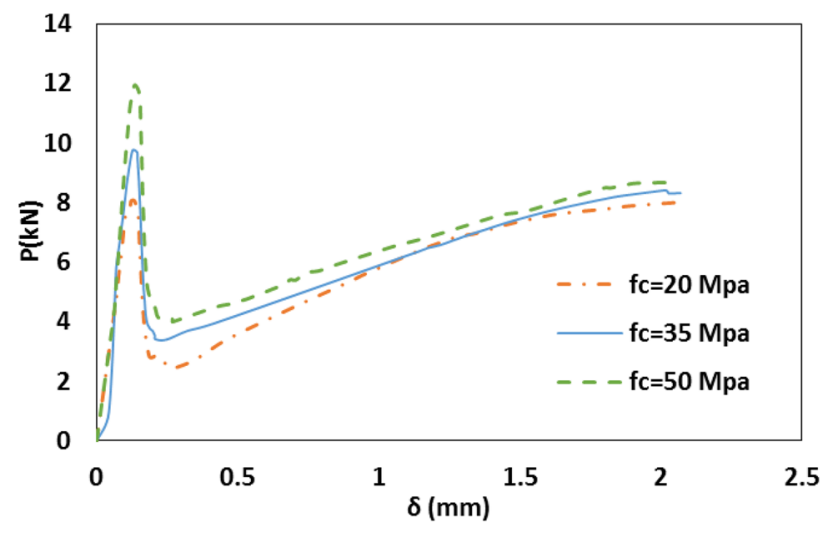

Fig. 19 The effect of concrete strength on $\mathrm{P}-\delta$ curve

$G_{f}=73\left(f_{c k}+8\right)^{0.18}$

Concrete mechanical properties for parametric analysis with Abaqus are reported in Table 3.

The $\mathrm{P}-\delta$ curve of mix designs with concrete strengths of 20, 35 and $50 \mathrm{MPa}$ is illustrated in Fig. 19.

It is recognized that an increase in concrete strength, escalates the two peak points. Therefore, the first peak load increases by $40 \%$ with concrete strength increment. Such value is $10 \%$ for $\mathrm{P}_{2 \max }$ considering the respective strengths. Because the bond stress in the fracture process area in the notch vicinity and the interfacial lamina-toconcrete shear strength are commensurate with concrete tensile strength.

\subsection{The effect of change in notch location}

In order to investigate the effect of initial notch location on the bearing capacity and specimen failure, the relative distance of notch from mid-span is assumed to be the three values of $a=c / l=0,1 / 3$ and $2 / 3$, where $I$ is half the length of beam span. Concrete strength is $35 \mathrm{MPa}$ and the properties of CFRP are presented in Table 2. Also, Fig. 20 shows the crack propagation process for the above models.

Based on the numerical analyses, failure process of specimens with $c / l=1 / 3$ and $c / l=2 / 3$ is initiated with diagonal cracking above the notch, and then crack propagates towards the loading point, causing the element at the top of the notch reach the critical fracture energy of concrete.

When the initial notch location moves away from midspan, the crack extension path inclines and then moves to the point of maximum bending moment. Figure 21 presents the $P-\delta$ curve for three models with $a=0,1 / 3$, $2 / 3$. As the initial notch moves away from mid-span, the load-carrying capacity of beam increases; so that the first peak load in $c / I=1 / 3$ and $2 / 3$, compared with the mid-span initial notch, are 5.5 and $116 \%$ respectively. Additionally, when the relative distance of notch from mid-span is equal to $a=1 / 3$ and $2 / 3$, compared to model with $a=0$, the second peak load increases by 39 and $58 \%$, respectively.

The maximum bending moment occurs at mid-span under the three-point load. Therefore, the location of initial crack at this critical point $(a=0)$ increases the CFRP lamina stress, and consequently reduces the load-carrying capacity in the cross-section, compared to other models $(a=1 / 3$ and $2 / 3$ ).

Fig. 20 Crack propagation in CFRP strengthened beams: a $c / I=0 ; \mathbf{b} c / I=1 / 3 ; c c / I=2 / 3$

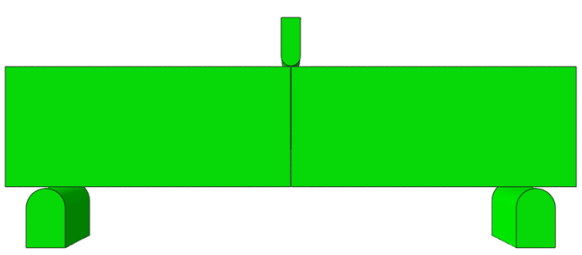

(a)

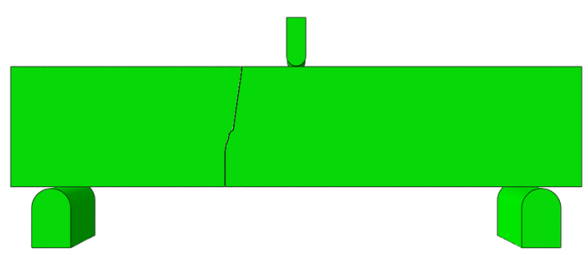

(b)

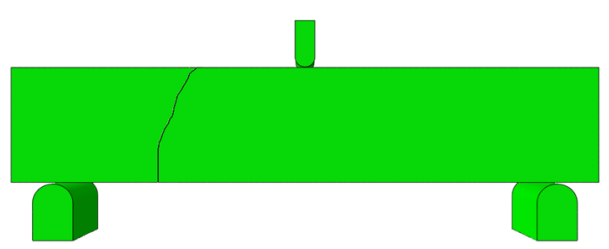

(c) 


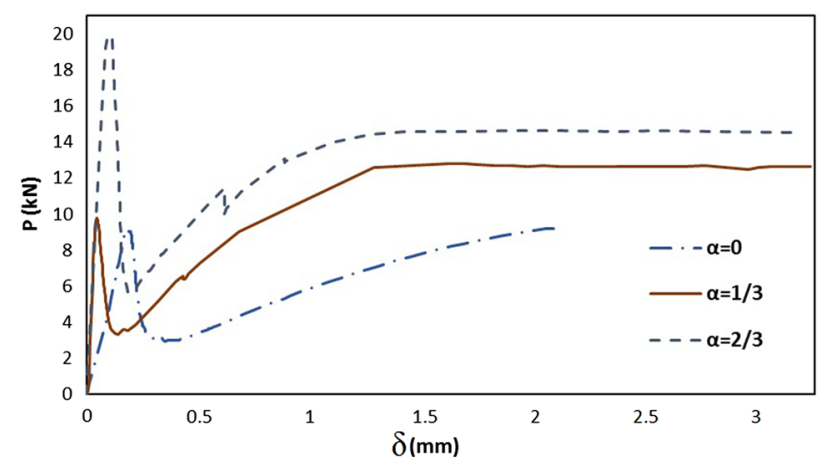

Fig. $21 \mathrm{P}-\delta$ curves for $a=0,1 / 3$ and $2 / 3$

\section{Concluding remarks}

The present study investigated the effects of strengthening notched SCC beams with CFRP lamina, on the failure mode and crack propagation process. A total of five classes of beams with adaptable $\mathrm{a}_{0} / \mathrm{h}$ ratios and beam heights were then cast and exposed to three-point loading. Further, numerical models of specimens were developed, and then the experimental measures were compared to FE predictions. Subsequently, the performance of concrete beams were also assessed via FE approach by varying several influential parameters. The following results were consequently drawn:

- On the basis of experimental and numerical data, it was noticed that load-displacement diagrams feature two maximum values. Once the load is applied, a vertical crack is propagated and then the first peak point is reached. Then a decrease ensues in the bearing capacity by about $35 \%$. Afterwards, an expansion in the midspan displacement leads to a rise in the CFRP stress, and the load-carrying capacity is escalated to reach the second peak point.

- The specimen failure mechanism involves: vertical growth of crack; debonding of CFRP lamina adjacent to initial notch; debonding evolution in the support direction; and eventually full crack development up to the upper face of the beam. According to numerical analyses, when the bearing capacity reaches $\mathrm{P}_{1 \max }$ cracking surmounts slightly more than half the beam height. Following its vertical expand to the point of loading, there is a sharp decline in the $\mathrm{P}-\delta$ graph. Then the capacity reaches the second peak point with stress increasing in the lamina.

- It was also witnessed that the $P_{1 \max }$ decreases by about $55 \%$, with increasing initial notch length 5 , however, the $P_{2 \max }$ was unchanged.
- According to results analyses, it was found that with increasing the section height, the first and second peak loads increase 30 and $10 \%$, respectively.

- By numerically quantifying the effects of concrete strength, CFRP lamina elastic modulus, and bond strength on the load- midspan displacement curve, it was observed that the impact of concrete strength on $\mathrm{P}_{1 \text { max }}$ is nearly $40 \%$. With regard to other parameters, the second peak load is more dependent on the CFRP lamina elastic modulus, as well as the interfacial bond strength.

- As the initial notch moves away from mid-span, $P_{1 \max }$ and $P_{2 \max }$ significantly increase by about 116 and $58 \%$, respectively. Hence, the structure represents more ductile behavior at $a=0$, in which the initial notch is located at the point of maximum bending moment at mid-span.

\section{Compliance with ethical standard}

Conflict of interest On behalf of all authors, the corresponding author states that there is no conflict of interest.

\section{References}

1. Muciaccia G, Cattaneo S, Rosati G, Cangiano S (2015) Properties of limestone self-compacting concrete at fresh and hardened state. Eur J Environ Civ Eng 19(5):598-613

2. Adesina A, Awoyera P (2019) Overview of trends in the application of waste materials in self-compacting concrete production. SN Appl Sci 1(9):962

3. Leemann A, Münch B, Gasser P, Holzer L (2006) Influence of compaction on the interfacial transition zone and the permeability of concrete. Cem Concr Res 36(8):1425-1433

4. Rozière $E$, Granger $S$, Turcry $P$, Loukili $A$ (2007) Influence of paste volume on shrinkage cracking and fracture properties of self-compacting concrete. Cement Concr Compos 29(8):626-636

5. Zhao Y, Ma J, Wu Z, Xu S, Gao H (2005) Study of fracture properties of self-compacting concrete using wedge splitting test. In: SCC'2005-China: 1st international symposium on design, performance and use of self-consolidating concrete, pp 421-428

6. CEB-FIP, (Fédération International de la Précontrainte) (1993) CEB-FIP model cod 1990. Thomas Telford, Lausanne

7. Eskandari H, Muralidhara S, Raghuprasad BK, Reddy BV (2010) Size effect in self consolidating concrete beams with and without notches. Sadhana 35(3):303-317

8. Beygi MH, Kazemi MT, Nikbin IM, Amiri JV (2013) The effect of water to cement ratio on fracture parameters and brittleness of self-compacting concrete. Mater Des 50:267-276

9. Beygi MH, Kazemi MT, Amiri JV, Nikbin IM, Rabbanifar S, Rahmani E (2014) Evaluation of the effect of maximum aggregate size on fracture behavior of self-compacting concrete. Constr Build Mater 55:202-211 
10. Beygi MH, Kazemi MT, Nikbin IM, Amiri JV (2014) The effect of aging on the fracture characteristics and ductility of self-compacting concrete. Mater Des 55:937-948

11. Nikbin IM, Beygi MHA, Kazemi MT, Amiri JV, Rahmani E, Rabbanifar S, Eslami M (2014) Effect of coarse aggregate volume on fracture behavior of self-compacting concrete. Constr Build Mater 52:137-145

12. Rajaram M, Ravichandran A, Muthadhi A (2019) Flexural performance of over-reinforced beam containing hybrid fibres with GGBS. SN Appl Sci 1(7):752

13. Mieda G, Nakamura H, Matsui T, Ochi Y, Matsumoto $Y$ (2019) Mechanical behavior of CFRP on steel surface molded and bonded by vacuum-assisted resin transfer molding technology. SN Appl Sci 1(6):601

14. Rathod RSB, Goel MD, Chakraborty T, Matsagar V, Guégan P, Binetruy $C$ (2019) Experimental and numerical investigations on dynamic behavior of CFRP laminates. SN Appl Sci 1(7):736

15. Al-Tamimi AK, Hawileh R, Abdalla J, Rasheed HA (2011) Effects of ratio of CFRP plate length to shear span and end anchorage on flexural behavior of SCC RC beams. J Compos Constr 15(6):908-919

16. Wu Z, Yang S, Hu X, Zheng J, Fan X, Shan J (2010) Analytical solution for fracture analysis of CFRP sheet-strengthened cracked concrete beams. J Eng Mech 136(10):1202-1219
17. Zhang D, Wang Q, Dong J (2016) Simulation study on CFRP strengthened reinforced concrete beam under four-point bending. Comput Concr 17(3):407-421

18. Achintha M, Burgoyne $C$ (2013) Fracture energy of the concreteFRP interface in strengthened beams. Eng Fract Mech 110:38-51

19. Zheng JJ, Dai JG, Fan XL (2015) Fracture analysis of FRP-Plated notched concrete beams subjected to three-point bending. J Eng Mech 142(3):04015096

20. Mohammadi T, Wan B, Harries KA, Sweriduk ME (2017) Bond behavior of FRP-concrete in presence of intermediate crack debonding failure. J Compos Constr 21(5):04017018

21. EFNARC S (2002) Guidelines for self-compacting concrete. Association House, London, UK, 32, 34

22. Shah SP, Swartz SE, Ouyang C (1995) Fracture mechanics of concrete: applications of fracture mechanics to concrete, rock and other quasi-brittle materials. Wiley, Hoboken

23. Lu XZ, Teng JG, Ye LP, Jiang JJ (2005) Bond-slip models for FRP sheets/plates bonded to concrete. Eng Struct 27(6):920-937

Publisher's Note Springer Nature remains neutral with regard to jurisdictional claims in published maps and institutional affiliations. 